\section{$\underset{\substack{\text { hommes } \\ \text { \& migrations }}}{ }$}

\section{Hommes \& migrations}

Revue française de référence sur les dynamiques

migratoires

$1326 \mid 2019$

Londres et ses migrations

\title{
Sinan Antoon, Ave Maria
}

\section{Mustapha Harzoune}

\section{(QpenEdition \\ Journals}

\section{Édition électronique}

URL : https://journals.openedition.org/hommesmigrations/9930

DOI : 10.4000/hommesmigrations.9930

ISSN : 2262-3353

\section{Éditeur}

Musée national de l'histoire de l'immigration

\section{Édition imprimée}

Date de publication : 1 juillet 2019

Pagination : 186-187

ISBN : 978-2-919040-46-9

ISSN : $1142-852 X$

\section{Référence électronique}

Mustapha Harzoune, «Sinan Antoon, Ave Maria », Hommes \& migrations [En ligne], 1326 | 2019, mis en ligne le 01 juillet 2019, consulté le 16 janvier 2022. URL : http://journals.openedition.org/ hommesmigrations/9930; DOI : https://doi.org/10.4000/hommesmigrations.9930 


\section{Ave Maria}

Sinan Antoon, traduit de l'arabe (Irak) par Philippe Vigreux,

Paris/Arles, Sindbad/Actes Sud, 2018, 182 pages, $21 €$.

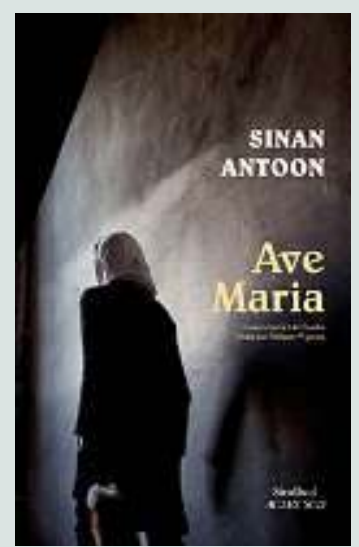

Ave Maria évoque la situation des chrétiens en Irak et la question de leur départ. De mère américaine et de père irakien, l'auteur a grandi à Bagdad. Dès les premières lignes, l'écriture surprend, envoûte. Comme en contrepoint, la prose avance, 
construit un espace de quiétude, une bulle dans un environnement de bruits et de démence. Le lecteur pénètre dans cette atmosphère emprunte d'intériorité, de régularité, découvre l'intérieur paisible d'une maison où se mêlent icônes, vierges, croix, photos d'hommes d'Églises et objets divers. Le récit progresse, lentement, au rythme des pensées et des descriptions de Youssef. C'est lui qui, par son calme, sa bonté, sa douceur, donne le ton. Retraité, ce spécialiste des palmiers semble filer des jours tranquilles dans une Bagdad de dangers et de menaces.

Tout commence par une dissension entre Youssef et Maha, sa jeune et attentive nièce. Quand Maha dénonce les persécutions et les dangers qui menacent les chrétiens, Youssef ne veut voir que des questions «de politique et d'intérêt, pas de religion». "Pour fuir le vacarme et la laideur du monde», il fait du passé un refuge et, du fait de l'antériorité de la présence chrétienne, il demande: "si ce n'est pas notre pays, alors c'est celui de qui, tu peux me le dire?». «Mais quelle histoire? répond Maha. Je t'en prie. Tu vois bien, mon oncle, que tu vis dans le passé!»

Et la question tourmente Youssef. Avec lui, le lecteur se déplace dans la maison, retrace l'histoire de cette famille éclatée, "surtout après $2003 »$, qui aux États-Unis, au Canada, en Nouvelle-Zélande ou en
Suède. Et lui, qui refuse de partir. Les photos de famille restent les seuls témoins de ce passé. Elles scandent les vicissitudes politiques du pays. Youssef serait-il le vestige suranné d'un temps disparu? Et Maha l'incarnation d'une jeunesse lucide et sans illusions? Youssef se confie à son vieil ami Saadoun. Ensemble, comme membres de "l'état-major des opérations nuwasiennes», ils ont chanté Omar Khayyam, déclamé des vers bachiques, classiques et ceux de la jâhilîya. Saadoun, le musulman, a assisté aux enterrements des membres de la famille de Youssef, il a prononcé la Fatiha pour les défunts. "Nous sommes des antiquités» reconnaît Saadoun, renvoyant du même coup cette riche culture et cette liberté de ton au... passé. À l'heure où même les palmiers sont chiites ou sunnites, Youssef et Saadoun réveillent «un temps où le communautarisme n'existait pas!» Pourtant, les amours de Youssef le chrétien et de Dalal la musulmane se sont brisées des années plus tôt sur le mur du refus des deux familles. Pourtant, ils se récitent ces vers écrits dans les années 1940 par le poète Al-Jawâhiri: «Tartarins, tartarinades, / Avancées et reculades / Une fois chiite, une fois sunnites, / Une fois juif, une fois chrétien, / Kurde aujourd'hui, arabe demain!» Le communautarisme ne daterait donc pas d'hier? «Oui, m'sieur! Il y a toujours eu des sunnites et des chiites, des chrétiens et des musulmans. Et tout ça sans massacres ni exterminations, ni milices, ni voitures piégées!» Pour eux, tout serait «venu récemment, de toutes ces ingérences, de cette haine envers nous et de cette mafia étrangère qui nous gouverne et nous a ramené toute cette merde!»

Du Canada, Amal demande à son frère de partir. "Et où j'irais à mon âge, pour mener une vie de misère? (...) Je préfère la mener ici, dans mon pays» répond Youssef. Mais ce pays est-il encore le sien? Alors, Maha raconte, les humiliations quotidiennes d'une chrétienne, sans hijab donc, dans les rues de Bagdad, les rebuffades de l'administration, les préjugés et les persécutions. Tandis que sur Facebook des nostalgiques pleurent «le bel Irak», elle écrit «quand je regarde toutes ces photos et les commentaires qui les suivent, je me rends compte que je n'ai même pas de jours heureux que je pourrais regretter! (...) Nous leur laisserons le pays pour qu'ils le brûlent, exhibent son cadavre et versent des larmes dessus une fois qu'il sera trop tard... ».

Youssef ne s'est pas encore «réconcilié » avec Maha. Il pense le faire à l'église à l'occasion de la messe d'anniversaire de la mort d'Hinna, sa sœur dévote et dévouée, morte en 2003. L'heure des retrouvailles et des vérités.

M. H. 